\title{
Compatible stability of methylprednisolone sodium succinate and tropisetron in $0.9 \%$ sodium chloride injection
}

\author{
Chen Peng $\odot,{ }^{1}$ Jie-Xin Lei ${ }^{2}$
}

'Department of Pharmacy, Renmin Hospital of Wuhan University, Wuhan, People's Republic of China

${ }^{2}$ Department of Endocrinology, Renmin Hospital of Wuhan University, Wuhan, People's Republic of China

Correspondence to Chen Peng, Department of Pharmacy, Renmin Hospital of Wuhan University, Wuhan 430060, People's Republic of China; 2282968908@qq.com

Received 25 July 2018 Revised 6 November 2018 Accepted 12 November 2018 Published Online First 1 December 2018

EAHP Statement 4: Clinical Pharmacy Services.
D Check for updates

(C) European Association of Hospital Pharmacists 2020. No commercial re-use. See rights and permissions. Published by BMJ.

To cite: Peng C, Lei J-X. Eur I Hosp Pharm

2020:27:e58-e62.

\section{ABSTRACT}

Background A combination of methylprednisolone sodium succinate and tropisetron hydrochloride is commonly used to treat the nausea and vomiting associated with antineoplastic therapy. The objective of this study was to investigate the stability of tropisetron hydrochloride and methylprednisolone sodium succinate in $0.9 \%$ sodium chloride injection for up to 48 hours. Methods Commercial solutions of methylprednisolone sodium succinate and tropisetron hydrochloride were obtained and further diluted with $0.9 \%$ sodium chloride injection to final concentrations of either 0.4 or $0.8 \mathrm{mg} /$ $\mathrm{mL}$ (methylprednisolone sodium succinate) and $0.05 \mathrm{mg} /$ $\mathrm{mL}$ (tropisetron). The admixtures were assessed for periods of up to 48 hours after storage at $4^{\circ} \mathrm{C}$ with protection from light and at $25^{\circ} \mathrm{C}$ without protection from light. Physical compatibility was determined visually, and the chemical compatibility was measured with high-performance liquid chromatography (HPLC) and by measurement of $\mathrm{pH}$ values.

Results HPLC analysis demonstrated that methylprednisolone sodium succinate and tropisetron hydrochloride in the various solutions were maintained at $97 \%$ of the initial concentrations or higher during the testing period. There were no changes observed by physical precipitation or $\mathrm{pH}$ in any of the prepared solutions.

Conclusions Tropisetron hydrochloride injection and methylprednisolone sodium succinate injection in 0.9\% sodium chloride injection are stable for up to 48 hours at $4^{\circ} \mathrm{C}$ and $25^{\circ} \mathrm{C}$.

\section{INTRODUCTION}

Patients receiving chemotherapy for cancer often experience nausea and vomiting, which are distressing adverse events that can be prevented or treated with a variety of antiemetic agents. ${ }^{1}$ Tropisetron hydrochloride $\left(\mathrm{C}_{17} \mathrm{H}_{20} \mathrm{~N}_{2} \mathrm{O}_{2} \cdot \mathrm{HCl}\right)$, 1H-indole-3-carboxylic acid (3-endo)-8-methyl-8azabicyclo[3.2.1] oct-3-yl ester hydrochloride, is a selective 5-hydroxytryptamine-3 $\left(5-\mathrm{HT}_{3}\right)$ receptor antagonist and has been widely administered for the prevention and treatment of nausea and vomiting associated with antineoplastic therapy. ${ }^{2}$ The structures of the drugs are shown in figure 1A.

Combination antiemetic therapy has become the standard procedure for the prevention of these gastrointestinal effects caused by anticancer drugs. ${ }^{3}$ It has been confirmed that the effectiveness of specific serotonin agonists could be enhanced by concomitant use of injectable corticosteroids such as dexamethasone and methylprednisolone. Methylprednisolone sodium succinate $\left(\mathrm{C}_{26} \mathrm{H}_{33} \mathrm{NaO}_{8}, 11 \beta, 17 \alpha, 21\right.$-trihydroxy$6 \alpha$-methylpregna-1,4-diene-3,20-diketone-21-sod ium succinate, figure 1B), which is a soluble prodrug of methylprednisolone, has been administered in combination with other types of antiemetics and is sometimes used instead of dexamethasone. ${ }^{45}$ The in vitro compatibility of tropisetron hydrochloride and dexamethasone has been investigated, but the stability of tropisetron hydrochloride with methylprednisolone sodium succinate has not been reported. ${ }^{6}$

Many hospitals have established pharmacy intravenous admixture (PIVA) services, and they carry out a centralised preparation service for anticancer and other drugs, so it is sometimes desirable to prepare multiple doses in advance and store them frozen or refrigerated until use. ${ }^{2}$ Therefore, information regarding the chemical stability and compatibility of these drugs in infusion solutions is required to evaluate the feasibility of such a practice. ${ }^{89}$ The objective of this study was to assess the stability of methylprednisolone sodium succinate and tropisetron in polyolefin bags of $0.9 \%$ sodium chloride injection stored at $4^{\circ} \mathrm{C}$ and $25^{\circ} \mathrm{C}$.

\section{METHODS}

\section{Materials and reagents}

Methylprednisolone sodium succinate (lot 121350, chemical purity 99.7\%) and tropisetron (lot 121432, chemical purity 99.8\%) reference standards were purchased from Beijing Guangyuan Hengxin Technology Development (Beijing, People's Republic of China). Commercially available ampoules of methylprednisolone sodium succinate injection $(40 \mathrm{mg} /$ $\mathrm{mL}$, lot 17062793) were obtained from Hengrui Medicine (Jiangsu, People's Republic of China). Tropisetron hydrochloride injection $(1 \mathrm{mg} / \mathrm{mL}$, lot 20170402) was obtained from CommScope Pharmaceutical (Hunan, People's Republic of China). The $0.9 \mathrm{mg} / \mathrm{mL}$ sodium chloride injection, which was used to prepare the sample mixtures, was supplied by Kelun Pharmaceutical (Sichuan, People's Republic of China, lot A1508226). All other chemicals used were of analytical grade and purchased from Guoyao Chemical Reagent (Shanghai, China) if not otherwise stated.

\section{Instrumentation}

Each sample was analysed by high-performance liquid chromatography (HPLC) to quantify the components. The HPLC system (Ultimate 3000, Dionex, Germering, Germany) consisted of a 


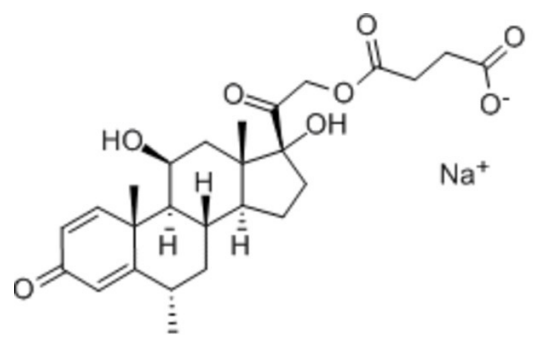

A

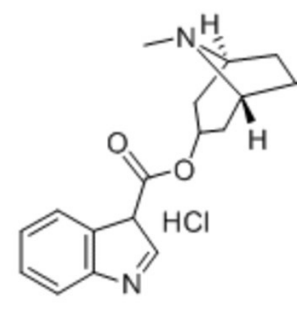

B
Figure 1 Chemical structures of $(A)$ methylprednisolone sodium succinate and (B) tropisetron hydrochloride.

quaternary liquid gradient system, WPS-3000RS autoinjector, TCC-100 column oven and DAD-3000RS UV spectrophotometer. Chromatographic data were acquired using Chromeleon software V.6.80. The $\mathrm{pH}$ values for the samples at each designated time interval were measured with a $\mathrm{pH}$ metre (Model pHS-3C, Leici Instrument, Shanghai, China).

\section{Chromatographic conditions}

Chromatographic separation was performed using a $1.9 \mu \mathrm{m}$ Hypersil Gold $\mathrm{C}_{18}$ column $(100 \mathrm{~mm} \times 2.1 \mathrm{~mm}$, Thermo Fisher Scientific, USA). The column was maintained at a temperature of $25^{\circ} \mathrm{C}$, and the gradient operated at a flow rate of $0.5 \mathrm{~mL} / \mathrm{min}$ with a $10 \mu \mathrm{L}$ injection volume for each sample. The mobile phase was composed of $0.1 \%$ formic acid in $\mathrm{KH}_{2} \mathrm{PO}_{4}$ in water (A) and $0.1 \%$ formic acid in acetonitrile (B) in the ratio of $70: 30(\mathrm{v} / \mathrm{v})$ throughout the analysis. ${ }^{10}$ The selected detection wavelengths for methylprednisolone sodium succinate and tropisetron were 245 and $285 \mathrm{~nm}$, respectively. ${ }^{11}$

\section{Preparation and storage of admixtures}

To simulate the drug concentrations encountered in practice, the reagents were combined in intravenous solutions at the following final nominal concentrations: tropisetron $0.05 \mathrm{mg} /$ $\mathrm{mL}$ and methylprednisolone sodium succinate 0.4 or $0.8 \mathrm{mg} / \mathrm{mL}$. Control solutions including tropisetron or methylprednisolone sodium succinate alone were prepared. All samples were then frozen at $-20^{\circ} \mathrm{C}$ until analysis. ${ }^{12}$

\section{Method validation}

The validation of the proposed method was performed in terms of linearity range, accuracy, intraday and interday precision and stability indication for tested drugs.

\section{Linearity}

Calibration curves were constructed from a linear plot of peak area versus concentration of the reference standards for tropisetron $(0.004-0.096 \mathrm{mg} / \mathrm{mL})$ and methylprednisolone sodium succinate $(0.020-0.400 \mathrm{mg} / \mathrm{mL}) .^{13}$

\section{Precision and accuracy}

Quality control samples of tropisetron hydrochloride (40.0, 80.0 and $120 \mu \mathrm{g} / \mathrm{mL}$ ) and methylprednisolone sodium succinate hydrochloride $(200,400$ and $800 \mu \mathrm{g} / \mathrm{mL})$ were used for calculation of the accuracy and intraday/interday precisions. The accuracy was calculated based on drug recovery from the solvents. The precision was calculated as the coefficient of relative SD (\%) within a single run (intraday) and among different runs (interday). Each sample was analysed in triplicate (total $n=3$ ).

\section{Stability study of drug solutions}

Three $100 \mathrm{~mL}$ polyolefin bags containing final nominal concentrations of tropisetron hydrochloride $(0.05 \mathrm{mg} / \mathrm{mL})$ and methylprednisolone sodium succinate $(0.4 \mathrm{or} 0.8 \mathrm{mg} / \mathrm{mL})$ mixture were stored in the dark at $4^{\circ} \mathrm{C}$ and $25^{\circ} \mathrm{C}$. The selection of the concentrations of these drugs in our study was based on those used in daily practice. At each time point (0, 2, 4, 6, 8, 24 and 48 hours), the appearance, $\mathrm{pH}$ and drug concentration were evaluated. Each sample was analysed in triplicate (total $n=3$ ).

\section{Stability indication}

Degradation of samples of methylprednisolone sodium succinate hydrochloride and tropisetron was assessed by chromatography to confirm the separation of the parent molecule from its degradation products. The mixed solutions of tropisetron with methylprednisolone sodium succinate in $0.9 \%$ sodium chloride injection were degraded by heating at $60^{\circ} \mathrm{C}$ for 5 hours in $0.1 \mathrm{~mol} / \mathrm{L}$ hydrochloric acid, $0.1 \mathrm{~mol} / \mathrm{L}$ sodium hydroxide and $3 \%$ hydrogen peroxide. After the degraded preparations were completed, they were assessed by HPLC assay. ${ }^{14}$ Each sample was analysed in triplicate (total $n=3$ ).

\section{Analysis of data}

Data are expressed as the mean $\pm \mathrm{SD}$. The initial concentration of methylprednisolone sodium succinate hydrochloride and tropisetron was defined as $100 \%$, and the subsequent sample concentrations were expressed as percentages of the initial concentration. Compatibility was defined as no observation of precipitation or change in physical appearance. The drugs were considered to be stable if they retained $90 \%$ of the initial concentrations. The analysis was carried out by Statistical Package for the Social Sciences V.19.0 system (SPSS), and statistical significance between experimental groups was determined by a twoway analysis of variance followed by $\mathrm{t}$-tests. The difference was considered to be statistically significant when the $p$ value was less than 0.05 .

Table 1 Validation of HPLC method

\begin{tabular}{|c|c|c|c|c|}
\hline \multirow[b]{2}{*}{ Compound } & \multirow{2}{*}{$\begin{array}{l}\text { Measured concentrations, } \\
\mu \mathrm{g} / \mathrm{mL}\end{array}$} & \multirow[b]{2}{*}{ Accuracy, \% (n=3) } & \multicolumn{2}{|c|}{ Precision RSD, \% (n=3) } \\
\hline & & & Intraday & Interday \\
\hline \multirow[t]{3}{*}{ Tropisetron hydrochloride } & 40.0 & 101.2 & 0.7 & 1.3 \\
\hline & 80.0 & 99.8 & 0.4 & 0.8 \\
\hline & 120.0 & 99.9 & 1.1 & 1.8 \\
\hline \multirow[t]{3}{*}{ Methylprednisolone sodium succinate hydrochloride } & 200.0 & 100.4 & 0.9 & 1.9 \\
\hline & 400.0 & 99.7 & 0.5 & 0.9 \\
\hline & 800.0 & 101.5 & 1.0 & 1.4 \\
\hline
\end{tabular}

HPLC, high-performance liquid chromatography; RSD, relative SD. 

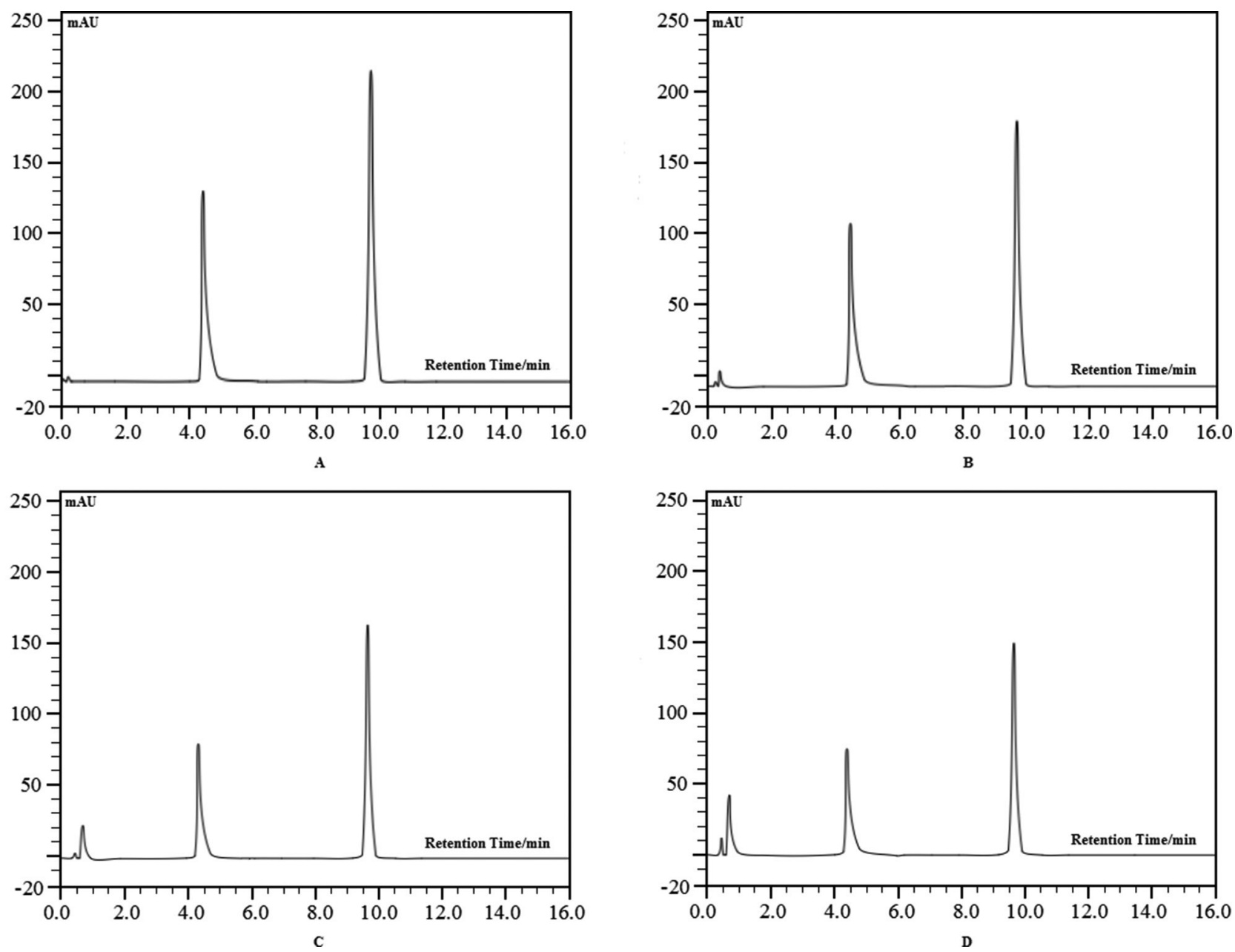

Figure 2 Chromatograms of tropisetron $0.025 \mathrm{mg} / \mathrm{mL}$ and methylprednisolone sodium succinate $0.6 \mathrm{mg} / \mathrm{mL}$ admixtures that were freshly prepared (A), exposed to $0.1 \mathrm{~mol} / \mathrm{L}$ hydrochloric acid at $60^{\circ} \mathrm{C}$ for 5 hours (B), exposed to $0.1 \mathrm{~mol} / \mathrm{L}$ sodium hydroxide at $60^{\circ} \mathrm{C}$ for 5 hours (C), and exposed to $3 \%$ hydrogen peroxide at $60^{\circ} \mathrm{C}$ for 5 hours (D). Retention times were $4.38 \mathrm{~min}$ for tropisetron (peak 1) and $9.67 \mathrm{~min}$ for methylprednisolone sodium succinate (peak 2).

\section{RESULTS}

\section{Validation of HPLC method}

The results of the accuracy and the intraday and interday precision of the assay method for the four analytes are shown in table 1. The data showed that the proposed HPLC method is accurate and precise for the quality control of tropisetron and methylprednisolone sodium succinate in the admixtures. There was a good linear response for both drugs between the peak area and concentration, with a correlation coefficient $(r)$ better than 0.9999. Under extreme conditions (strong acidic, basic and oxidation solutions), the degradation study results showed that the two drugs were stable, with less than 3\% decomposition into compounds that were baseline separated from all analytes (figure 2). The average retention times for methylprednisolone sodium succinate and tropisetron hydrochloride were 9.67 and $4.38 \mathrm{~min}$, respectively.

\section{Stability of mixtures of methylprednisolone sodium succinate} and tropisetron

Visual examinations of each admixture at each sampling time did not reveal any evidence of precipitation, turbidity, colour

Table 2 The $\mathrm{pH}$ of tropisetron in mixtures with methylprednisolone sodium succinate in $0.9 \%$ sodium chloride injection after storage at $4^{\circ} \mathrm{C}$ and $25^{\circ} \mathrm{C}($ mean $\pm \mathrm{SD} ; \mathrm{n}=3)$

\begin{tabular}{|c|c|c|c|c|}
\hline \multirow[b]{2}{*}{ Time (hours) } & \multicolumn{2}{|c|}{$\begin{array}{l}\text { Tropisetron }(0.05 \mathrm{mg} / \mathrm{mL})+\text { methylprednisolone sodium succinate } \\
(0.4 \mathrm{mg} / \mathrm{mL})\end{array}$} & \multicolumn{2}{|c|}{$\begin{array}{l}\text { Tropisetron }(0.05 \mathrm{mg} / \mathrm{mL})+\text { methylprednisolone sodium succinate } \\
(0.8 \mathrm{mg} / \mathrm{mL})\end{array}$} \\
\hline & $4^{\circ} \mathrm{C}$ & $25^{\circ} \mathrm{C}$ & $4^{\circ} \mathrm{C}$ & $25^{\circ} \mathrm{C}$ \\
\hline 0 & $7.04 \pm 0.1$ & $7.04 \pm 0.4$ & $7.28 \pm 0.1$ & $7.25 \pm 0.6$ \\
\hline 2 & $7.04 \pm 0.3$ & $7.02 \pm 0.2$ & $7.22 \pm 0.2$ & $7.17 \pm 0.4$ \\
\hline 4 & $7.06 \pm 0.5$ & $7.01 \pm 0.1$ & $7.18 \pm 0.4$ & $7.14 \pm 0.3$ \\
\hline 6 & $7.03 \pm 0.2$ & $6.98 \pm 0.2$ & $7.16 \pm 0.6$ & $7.13 \pm 0.5$ \\
\hline 48 & $7.06 \pm 0.2$ & $7.05 \pm 0.3$ & $7.12 \pm 0.2$ & $7.06 \pm 0.2$ \\
\hline
\end{tabular}


Table 3 Amount of initial concentration of tropisetron $(0.05 \mathrm{mg} / \mathrm{mL})$ with methylprednisolone sodium succinate $(0.4-0.8 \mathrm{mg} / \mathrm{mL})$ remaining after 48 hours of storage at $4{ }^{\circ} \mathrm{C}$ and $25^{\circ} \mathrm{C}(\%$; mean $\pm S D ; n=3)$

\begin{tabular}{|c|c|c|c|c|c|c|c|c|}
\hline \multirow[b]{2}{*}{$\begin{array}{l}\text { Time } \\
\text { (hours) }\end{array}$} & \multicolumn{2}{|l|}{$4^{\circ} \mathrm{C}$} & \multicolumn{2}{|l|}{$25^{\circ} \mathrm{C}$} & \multicolumn{2}{|l|}{$4^{\circ} \mathrm{C}$} & \multicolumn{2}{|l|}{$25^{\circ} \mathrm{C}$} \\
\hline & $\begin{array}{l}\mathrm{T} \\
(0.05 \mathrm{mg} / \mathrm{mL}, \%)\end{array}$ & $\begin{array}{l}M \\
(0.4 \mathrm{mg} / \mathrm{mL}, \%)\end{array}$ & $\begin{array}{l}\text { T } \\
(0.05 \mathrm{mg} / \mathrm{mL}, \%)\end{array}$ & $\begin{array}{l}M \\
(0.4 \mathrm{mg} / \mathrm{mL}, \%)\end{array}$ & $\begin{array}{l}\text { T } \\
(0.05 \mathrm{mg} / \mathrm{mL}, \%)\end{array}$ & $\begin{array}{l}M \\
(0.8 \mathrm{mg} / \mathrm{mL}, \%)\end{array}$ & $\begin{array}{l}\text { T } \\
(0.05 \mathrm{mg} / \mathrm{mL}, \%)\end{array}$ & $\begin{array}{l}M \\
(0.8 \mathrm{mg} / \mathrm{mL}, \%\end{array}$ \\
\hline 0 & 100 & 100 & 100 & 100 & 100 & 100 & 100 & 100 \\
\hline 2 & 99.9 & 99.7 & 99.5 & 99.0 & 100.2 & 99.9 & 99.7 & 100.3 \\
\hline 4 & 99.9 & 100.1 & 98.9 & 98.7 & 99.9 & 99.8 & 99.1 & 99.5 \\
\hline 6 & 99.8 & 99.9 & 98.7 & 98.4 & 99.8 & 99.8 & 98.6 & 98.7 \\
\hline 8 & 99.8 & 99.8 & 98.4 & 98.9 & 99.3 & 99.2 & 97.8 & 97.9 \\
\hline 24 & 99.3 & 99.2 & 98.2 & 98.7 & 99.2 & 98.4 & 97.9 & 97.5 \\
\hline 48 & 98.9 & 98.7 & 97.9 & 97.9 & 98.6 & 98.1 & 97.5 & 97.4 \\
\hline
\end{tabular}

$M$, methylprednisolone sodium succinate; $T$, tropisetron.

change, opacity or gas production during the study period. The initial $\mathrm{pH}$ of the admixtures ranged from 6.9 to 7.3 , and the changes were less than 0.12 throughout the study in all samples (table 2). Compatibility data are summarised in table 3, showing that no degradation products of the mixtures were observed over the 48 hours and that the final concentrations of tropisetron and methylprednisolone sodium succinate remaining in the admixtures were all greater than $97.6 \%$ of the starting concentration. Compatibility data of the solutions of tropisetron hydrochloride plus methylprednisolone sodium succinate revealed that the mixtures were stable for up to 48 hours at $4^{\circ} \mathrm{C}$ and $25^{\circ} \mathrm{C}$.

\section{DISCUSSION}

Vomiting and nausea are two of the major concerns in patients undergoing cancer chemotherapy, especially those patients who receive highly emetogenic drugs such as cisplatin. ${ }^{15} 16$ It is common practice to use drug combinations to prevent nausea and vomiting. Furthermore, there is an abundance of data in the literature confirming that coadministration of antiemetics from different classes could be a more effective antiemetic treatment modality, and methylprednisolone sodium succinate is a standard component of antiemetic combination regimens with $5-\mathrm{HT}_{3}$ antagonists. ${ }^{17} 18$ The combination of tropisetron (a $5-\mathrm{HT}_{3}$ receptor antagonist) with methylprednisolone sodium succinate in solutions to relieve chemotherapy-induced nausea and vomiting is now accepted, but there have been no reports to date about the compatibility and stability of such mixtures for clinical practice. ${ }^{19}$ Therefore, the present study aims to address this issue.

As mentioned previously, many studies have tested the stability and compatibility of methylprednisolone sodium succinate alone or in combination with other drugs in infusion solutions and suggested that methylprednisolone sodium succinate is a very stable drug. ${ }^{20-22}$ It was reported that precipitation could occur with tropisetron hydrochloride in combination with methylprednisolone sodium succinate or with tropisetron hydrochloride in an alkaline environment $(\mathrm{pH}>7) .{ }^{23}{ }^{24}$ In our study, no precipitation was observed. The absence of precipitation could be explained by the following: the low concentration of both drugs used in this study compared with those chosen by other investigators; the $\mathrm{pH}$ values of the mixture being, in most cases, less than 7; and the fact that tropisetron hydrochloride is a strong acid-weak base salt of $9.46 \mathrm{pKa}$, which would be strongly affected by $\mathrm{pH}$ (ie, it is stable in acidic solution and may precipitate and crystallise in alkaline solution). ${ }^{2526}$

In this experiment, the methods for the determination of methylprednisolone sodium succinate and tropisetron were adapted from the published literature. ${ }^{27}$ An acidic aqueous medium and acetonitrile were selected to start the optimisation of the mobile phase composition. Trials showed that an acidic mobile phase with a reverse-phase $\mathrm{C}_{18}$ column gives sharp peaks. In the present study, there was no modification of the chromatographic peaks in the binary mixtures of methylprednisolone sodium succinate and tropisetron hydrochloride at either of the temperatures. ${ }^{28}$ Based on our findings, it was credible that the combination of methylprednisolone sodium succinate and tropisetron hydrochloride in $0.9 \%$ sodium chloride injection is stable for up to 48 hours under all the storage conditions tested $\left(4^{\circ} \mathrm{C}\right.$ and $\left.25^{\circ} \mathrm{C}\right) .{ }^{29}$ The satisfactory compatibility and stability of methylprednisolone sodium succinate in combination with tropisetron hydrochloride means that licensed central services, such as PIVAs in hospitals, can be safely used to prepare these drugs.

When mixing drugs taken from ampoules of sterile solutions, bacterial contamination may occur. In this study, we only examined the physicochemical stability of mixing drugs without considering the issue of microbial contamination. Hence, the standards for sterile preparations detailed in chapter 797 of the US Pharmacopoeia (USP, National Prescription) should be respected and enforced in clinical practice. ${ }^{30}$ According to these standards, the agents we analysed were classified as low-risk composite aseptic products. To ensure the stability of the drug, it must be handled within the standards of the USP, which states that the preparation could be stored for 48 hours at room temperature and 2 weeks when refrigerated. ${ }^{31}$

\section{CONCLUSION}

In conclusion, a new and validated HPLC method for the simultaneous quantification of methylprednisolone sodium succinate and tropisetron hydrochloride has been successfully developed. This method was successfully used to study the compatibility and stability of drug mixtures at concentrations common in clinical use. The results of the stability study showed that the

\section{What this paper adds}

What is already known on this subject

- Methylprednisolone sodium succinate combined with tropisetron is used to relieve chemotherapy-induced nausea and vomiting, enhancing compliance and therapeutic effects for patients with cancer.

\section{What this study adds}

- The combined solution of methylprednisolone sodium succinate and tropisetron can be safely prepared by the pharmacist and can be stored in a refrigerator for up to 48 hours at $4^{\circ} \mathrm{C}$. 
combination of $0.05 \mathrm{mg} / \mathrm{mL}$ tropisetron and $0.4-0.8 \mathrm{mg} / \mathrm{mL}$ methylprednisolone sodium succinate, prepared in $0.9 \%$ sodium chloride injection and stored in polyolefin bags, was chemically stable for at least 48 hours at $4^{\circ} \mathrm{C}$ and $25^{\circ} \mathrm{C}$.

Contributors CP and JXL conceived and designed the experiments. CP performed the experiments. CP and JXL analysed the data. CP wrote the paper.

Funding The authors have not declared a specific grant for this research from any funding agency in the public, commercial or not-for-profit sectors.

Competing interests None declared.

Patient consent Not required.

Provenance and peer review Not commissioned; externally peer reviewed.

\section{ORCID iD}

Chen Peng http://orcid.org/0000-0003-4936-2064

\section{REFERENCES}

1 Hamy-Petit AS, Belin L, Bonsang-Kitzis H, et al. Pathological complete response and prognosis after neoadjuvant chemotherapy for HER2-positive breast cancers before and after trastuzumab era: results from a real-life cohort. $\mathrm{Br} J$ Cancer 2016;114:44-52.

2 Abdel Messih HA, Ishak RA, Geneidi AS, et al. Nanoethosomes for transdermal delivery of tropisetron $\mathrm{HCl}$ : multi-factorial predictive modeling, characterization, and ex vivo skin permeation. Drug Dev Ind Pharm 2017:43:1-40.

3 Toda H, Kawazoe H, Yano A, et al. Antiemetic effectiveness and cost-saving of aprepitant plus granisetron is superior to palonosetron in gastrointestinal cancer patients who received moderately emetogenic chemotherapy. J Cancer 2017:8:1371-7.

4 Frontini R, Miharija-Gala T, Sykora J. EAHP survey 2010 on hospital pharmacy in Europe: parts 4 and 5. Clinical services and patient safety. European Journal of Hospital Pharmacy 2013;20:69-73.

5 Olby NJ, Muguet-Chanoit AC, Lim JH, et al. A placebo-controlled, prospective, randomized clinical trial of polyethylene glycol and methylprednisolone sodium succinate in dogs with intervertebral disk herniation. J Vet Intern Med 2016:30:206-14.

6 Chen FC, Wang LH, Guo J, et al. Simultaneous determination of dexamethasone, ondansetron, granisetron, tropisetron, and azasetron in infusion samples by HPLC with DAD Detection. J Anal Methods Chem 2017:2017:1-7.

7 Nomura K, Fujimoto Y, Taniguchi K, et al. [Prophylactic effect of tropisetron hydrochloride against nausea and vomiting in patients receiving chemotherapy for hematological malignancies]. Gan To Kagaku Ryoho 2007;34:1513-7.

8 Coriell SR, McFadden GB, Voorhees PW, et al. Stability of a planar interface during solidification of a multicomponent system. J Cryst Growth 1987;82:295-302.

9 Zhang $\mathrm{H}$, Wang Z, Liu D. A comprehensive review of stability analysis of continuoustime recurrent neural networks. IEEE Trans Neural Netw Learn Syst 2017;25:1229-62.

10 Radchenko V, Engle JW, Wilson JJ, et al. Formation cross-sections and chromatographic separation of protactinium isotopes formed in proton-irradiated thorium metal. Radiochim Acta 2016;104:291-304.

$11 \mathrm{Gu}$ J, Qin W, Chen F, et al. Long-term stability of tramadol and ketamine solutions for patient-controlled analgesia delivery. Med Sci Monit 2015;21:2528-34
12 Janů M, Brodská H, Vecka M, et al. Comparison of long-term stability of parenteral allin-one admixtures containing new lipid emulsions prepared under hospital pharmacy conditions. Medicina 2011;47:46-333.

13 Kirschenbaum BE, Cacace L, Anderson RJ, et al. Personnel time and preparation costs for compounded versus premixed intravenous admixtures in three community hospitals. Am J Hosp Pharm 1988;45:605-8.

14 Wang BM, Zhang Y, Li M. The preparation and pozzolanic activity of metakaolin admixtures. Key Eng Mater 2013:539:230-4.

15 Stiff PJ, Fox-Geiman MP, Kiley K, et al. Prevention of nausea and vomiting associated with stem cell transplant: results of a prospective, randomized trial of aprepitant used with highly emetogenic preparative regimens. Biol Blood Marrow Transplant 2013:19:49-55.

16 Yun MJ, Kim YH, Kim AR. Comparison of azasetron and ondansetron for preventing postoperative nausea and vomiting in patients undergoing gynecological laparoscopic surgery. Yonsei Med J 2010;51:88-92.

17 Pytka K, Socała K, Rapacz A, et al. HBK-14 and HBK-15, triple 5-HT ${ }_{1 A^{\prime}} 5-\mathrm{HT}_{7}$ and 5- $\mathrm{HT}_{3}$ antagonists with potent antidepressant- and anxiolytic-like properties, increase seizure threshold in various seizure tests in mice. Prog Neuropsychopharmacol Biol Psychiatry 2017;79:378-85.

18 Som A, Bhattacharjee S, Maitra S, et al. Combination of 5-HT3 antagonist and dexamethasone is superior to 5 -ht3 antagonist alone for ponv prophylaxis after laparoscopic surgeries: a meta-analysis. Anesth Analg 2016;123:1418-26.

19 Zhou C, Zhu Y, Liu Z, et al. 5HT3 Antagonists versus dexamethasone in the prevention of ponv in patients undergoing laparoscopic cholecystectomy: a meta-analysis of RCTs. Biomed Res Int 2016;2016:1-7

20 Cheng S, Gao W, Xu X, et al. Methylprednisolone sodium succinate reduces BBB disruption and inflammation in a model mouse of intracranial haemorrhage. Brain Res Bull 2016:127:226-33.

21 Fehlings MG, Wilson J, Aarabi B, et al. Guidelines for the management of patients with spinal cord injury: the use of methylprednisolone sodium succinate. The Spine Journal 2016;16:\$215

22 Karabey-Akyurek Y, Gurcay AG, Gurcan 0, et al. Localized delivery of methylprednisolone sodium succinate with polymeric nanoparticles in experimental injured spinal cord model. Pharm Dev Technol 2017;22:972-81.

23 Nahata MC, Morosco RS, Hipple TF. Stability of diluted methylprednisolone sodium succinate injection at two temperatures. Am J Hosp Pharm 1994;51:2157-9.

24 Bougouin C, Thelcide C, Crespin-Maillard F, et al. Compatibility of ondansetron hydrochloride and methylprednisolone sodium succinate in multilayer polyolefin containers. Am J Health Syst Pharm 2005:62:2001-5.

$25 \mathrm{Kim}$ C-H, Cho KY, Choi E-J, et al. Effect of P(ILA-CO-?CL) on the compatibility and crystallization behavior of PCL/PLLA blends. J App/ Polym Sci 2000;77:226-31.

26 Koike K, Hashimoto K, Takai N, et al. Tropisetron improves deficits in auditory P50 suppression in schizophrenia. Schizophr Res 2005;76:67-72.

27 Lee JN, Park C, Whitesides GM. Solvent compatibility of poly(dimethylsiloxane)-based microfluidic devices. Anal Chem 2003;75:6544-54.

28 Tregenza T, Wedell N. Genetic compatibility, mate choice and patterns of parentage: invited review. Mol Ecol 2000;9:1013-27.

29 Aubry A, Carotenuto V, Maio AD. Forcing multiple spectral compatibility constraints in radar waveforms. IEEE Signal Process Lett 2016;23:483-7.

30 Zeng J, Yang L, Liang Q, et al. Influence of the drug compatibility with polymer solution on the release kinetics of electrospun fiber formulation. J Control Release 2005; 105:43-51.

31 Chaves LL, Rolim LA, Gonçalves MLCM, et al. Study of stability and drug-excipient compatibility of diethylcarbamazine citrate. J Therm Anal Calorim 2013;111:2179-86. 